\title{
Studying the Urban Heat Island Using a Local Climate Zone Scheme
}

\author{
Zhihao Wang*, Wu Xing, Yi Huang, Tongan Xie \\ Faculty of Civil Engineering and Mechanics, Kunming University of Science and Technology, \\ 650500 Kunming, China
}

Received: 11 April 2016

Accepted: 12 June 2016

\begin{abstract}
With rapid urbanization and the rise of climate change awareness, policy makers and urban planners are seeking methods and schemes that consider the urban heat island (UHI) effect. In order to investigate to what extent a homogeneous urban fabric leads to a specific thermal pattern, a local climate zone (LCZ) scheme was utilized and classification has been applied in the urban areas of Chongqing. Urban indicators were calculated to match LCZ types of measurement points. Using a mobile measurement approach, we analyzed screen-height air temperature distribution inside local climate zones in both spring and summer. An apparent seasonal difference inside LCZs was found, with air temperature amplitude about $0.8^{\circ} \mathrm{C}$ in spring and $0.9^{\circ} \mathrm{C}$ in summer. The average air temperature difference in LCZ 1 was $2.9^{\circ} \mathrm{C}$ between the two seasons, while in LCZ H this difference was as high as $3.5^{\circ} \mathrm{C}$. The reasons why LCZ H had relatively high air temperature were explained and further investigation of UHI using LCZ scheme was proposed.
\end{abstract}

Keywords: local climate zone, mobile measurements, urban heat island

\section{Introduction}

Urban heat island (UHI), a term first coined in the 1940 s, refers to the atmospheric warmth of a city compared to the surrounding countryside. The amplitude of the UHI is usually expressed as the synchronous screen-height air temperature difference between urban and rural thermal sensors [1]. UHI is an unintended outcome of urbanization and this phenomenon occurs in almost all urban areas, which could also lead to increased energy demand and thermal discomfort [2]. Recognized causes of UHI are increases of radiative trapping by complicated urban morphology [3], a decrease in wind speed, energy storage in urban construction, a decrease of evapotranspiration

*e-mail: wangzhihao@kmust.edu.cn due to the reduction of pervious surfaces in urban areas, and the anthropogenic heat released from social and human activities [4].

To investigate the relationships between local climate and urban fabric, researchers have developed classifications such as the flux ratio-active index surface exchange (FRAISE) scheme [5], which defined urban zones that characterize energy partitioning (UZE). Since urban environments can reflect local climate modification to some extent, another approach aims to incorporate urban indicators in designing a climate classification. Urban climatic maps (UCMaps) are based on this approach. UCMaps are built using land use information, topographic information, and climatic data [6].

With the same idea, Oke proposed the urban climate zone (UCZ) scheme, a simple urban classification uses descriptors dealing with urban morphology and land use 
[7]. Based on UCZ, Stewart created the local climate zone (LCZ) scheme [8]. An LCZ is defined as an area with a minimum diameter of $400 \mathrm{~m}$ and that demonstrates both uniform features in terms of urban morphology, land use, urban material, urban metabolism, and a characteristic screen-height temperature regime under a calm and clear sky.

One major advantage of the LCZ scheme is the possibility of redefining urban heat island magnitude as most UHI studies were using urban-rural dichotomy to calculate UHI magnitude and it may be misleading, besides, these adjectives may be too simple to describe the complex layout of cities. The LCZ scheme provides standard datasheets for each local climate zone and defines UHI magnitude as the difference of screen-height air temperature between two specific LCZs. The UCZ and LCZ schemes have been applied in Glasgow (UK) [9], Toulouse (France) [10], Nagano (Japan), Vancouver (Canada), and Uppsala (Sweden) [11], and have provided an overview of the air temperature distribution in these cities.

This work aims to apply the LCZ scheme in the urban areas of Chongqing in order to investigate to what extent homogeneous urban fabric leads to a specific thermal pattern. We analyzed the air temperature distribution inside LCZs in both spring and summer.

\section{Material and Methods}

\section{Site Description}

Chongqing, which numbers approximately 29 million inhabitants, is situated at $105^{\circ} 17^{\prime}-110^{\circ} 11^{\prime} \mathrm{E}$ and $28^{\circ} 10^{\prime}$ $32^{\circ} 13^{\prime} \mathrm{N}$, at the transitional area between the Qinghai-Tibet Plateau and the plain on the middle and lower reaches of

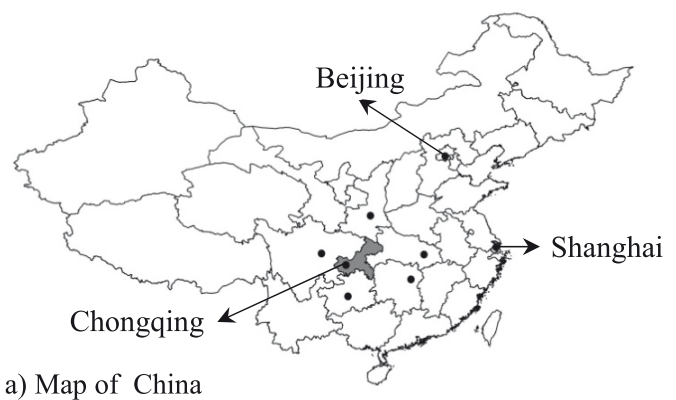

a) Map of China
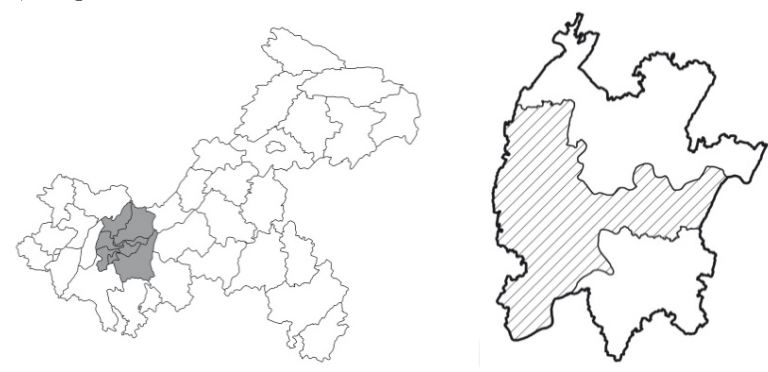

b) Map of Chongqing

c) Map of Chongqing Main City the Yangtze River in the sub-tropical climate zone swept by the moist monsoon (Fig. 1). The central urban area of Chongqing is a beautiful city with its unique features. Built on mountains and embraced by the Yangtze and Jialing rivers, it is known as the "mountain city" and the "city on rivers." The average annual temperature is around $18^{\circ} \mathrm{C}$, with the lowest winter temperature averaging between $6^{\circ} \mathrm{C}$ and $8^{\circ} \mathrm{C}$ and summer temperature averaging between $27^{\circ} \mathrm{C}$ and $29^{\circ} \mathrm{C}$. It has mild winter, hot summers, long frost-free periods, and ample rain, as well as warm, wet, and cloudy days, with rain and heat occurring in the same season. It is the largest economic center in the upper reaches of the Yangtze River and a key position of transportation on both land and water in southwest China.

\section{Micrometeorological Mobile Measurement}

The mobile measurement approach was chosen as it could probe the spatial air temperature distribution inside LCZs. The mobile measurement approach has been widely used in urban heat island or urban climate studies, such as in Krakow (Poland) [12], Debrecen (Hungary) [13], Singapore [14], Utrecht (Netherlands) [15], Leipzig (Germany) [16], and Nancy (France) [17]. This field experiment was targeted to take the advantages of the method, recording screen-height air temperature in numerous streets of an LCZ.

The research domain includes the Shapingba (SPB), Jiulongpo (JLP), Yuzhong (YZ), Dadukou (DDK), and Nan'an districts (NA), which are all in the urban areas of Chongqing, but with different functions. SPB, northwest of the main city, is the education and cultural center of Chongqing and is abundant in science and technology. JLP lies to the southwest and is the traditional industrial zone of Chongqing. YZ is the financial, commercial, and information center and plays the role of central business district for the city. DDK is the base of metallurgy, building materials, and physical distribution, which lies along the west bank of the Yangtze River. NA is the scientific

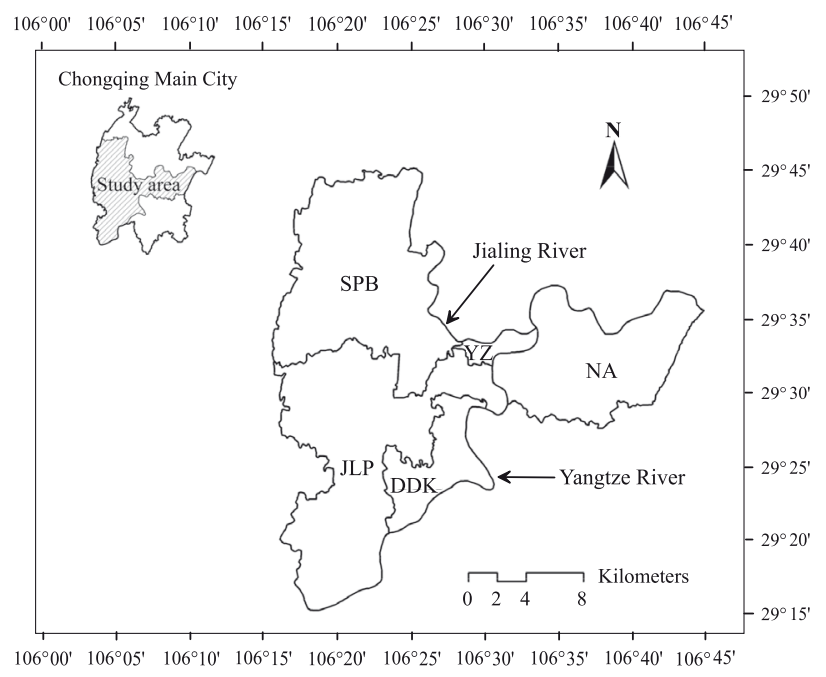

Fig. 2. Location of study areas in Chongqing main city.

Fig. 1. Location of Chongqing and its main city. 


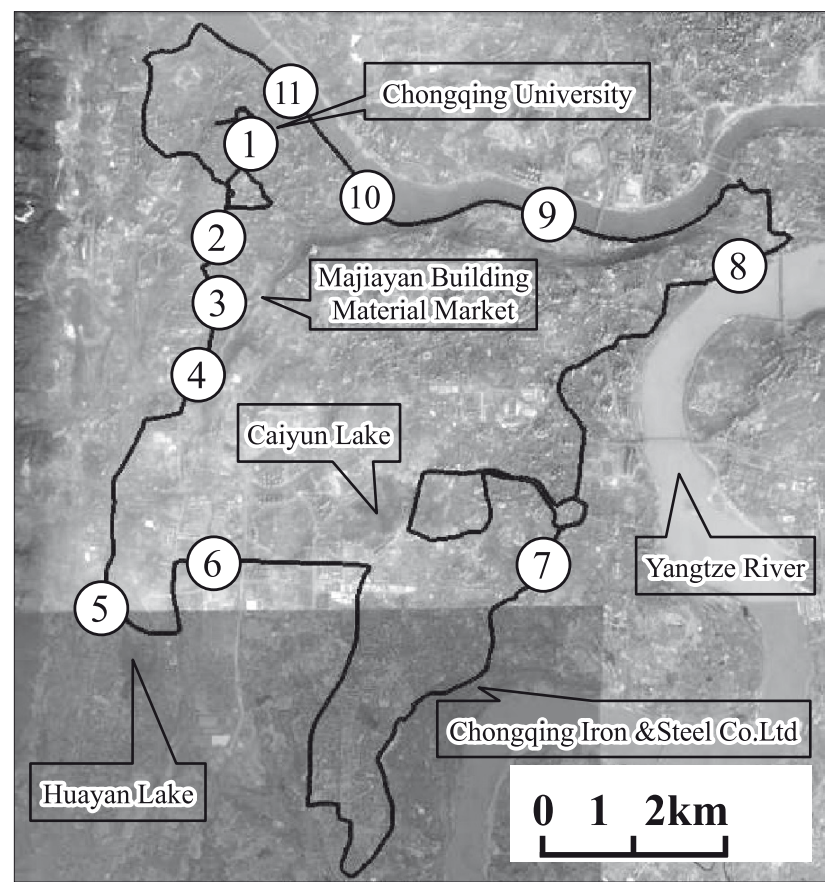

a) Route I

Fig. 3. Mobile measurement routes and selected measurement sites.

research base of Chongqing and hosts the national economic development zone. The locations of the above districts in Chongqing main city are shown in Fig. 2.

Measurements have been performed for low nebulosity and low wind speed with dry road surface in two selected seasons. Mobile measurements carried out on 18 and 25 May 2008 aimed to probe the spatial air temperature distribution inside the LCZ in spring, while measurements carried out on 29 and 30 July 2009 were of summer conditions. The measurement route of 2008 was defined as Route I. The duration time of measurements was from 14:00 to $16: 54$ on 18 May, and from 14:00 to $16: 58$ on 25 May. The measurement route of 2009 was defined as

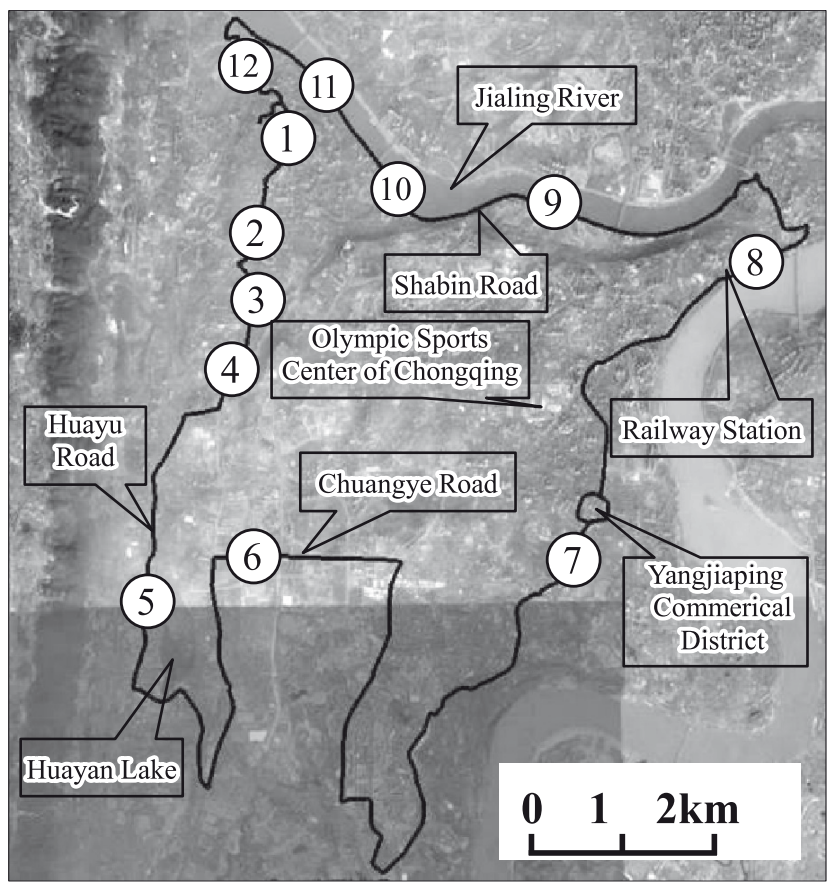

b) Route II

Route II. The duration time of measurements was from 14:05 to $16: 25$ on 29 July and from 14:02 to $16: 10$ on 30 July.

The differences of timespan were no more than 15 minutes. Considering that there were little changes in air temperature within those 15 minutes, the impact of the timespan differences on the results were neglected. Mobile measurement routes and selected measurement sites are shown in Fig. 3.

The length of Route I is 73.8 kilometers and Route II is 64.7 kilometers. The changes in elevation along the two routes are shown in Fig. 4. In both routes, the altitude changed a lot, from the lowest at $180 \mathrm{~m}$ (riverfront areas
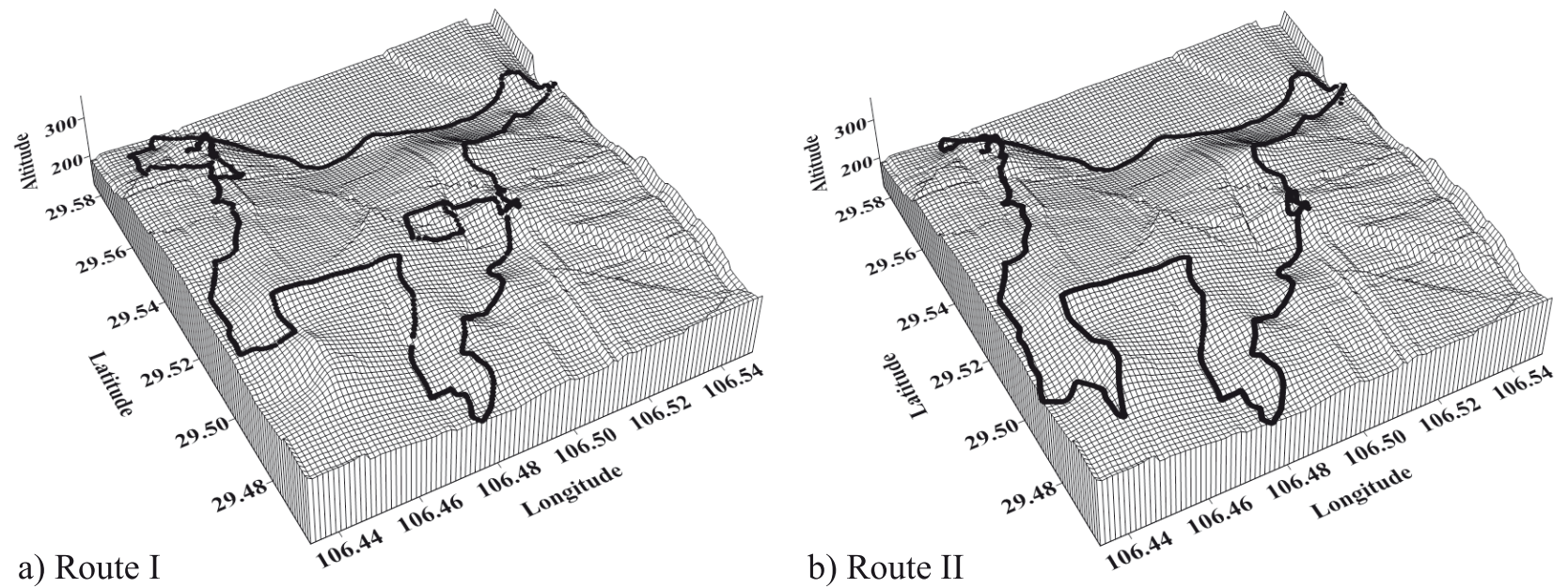

Fig. 4. Changes in elevation along two routes. 
Table 1. Metadata for classifying measurement sites into local climate zones.

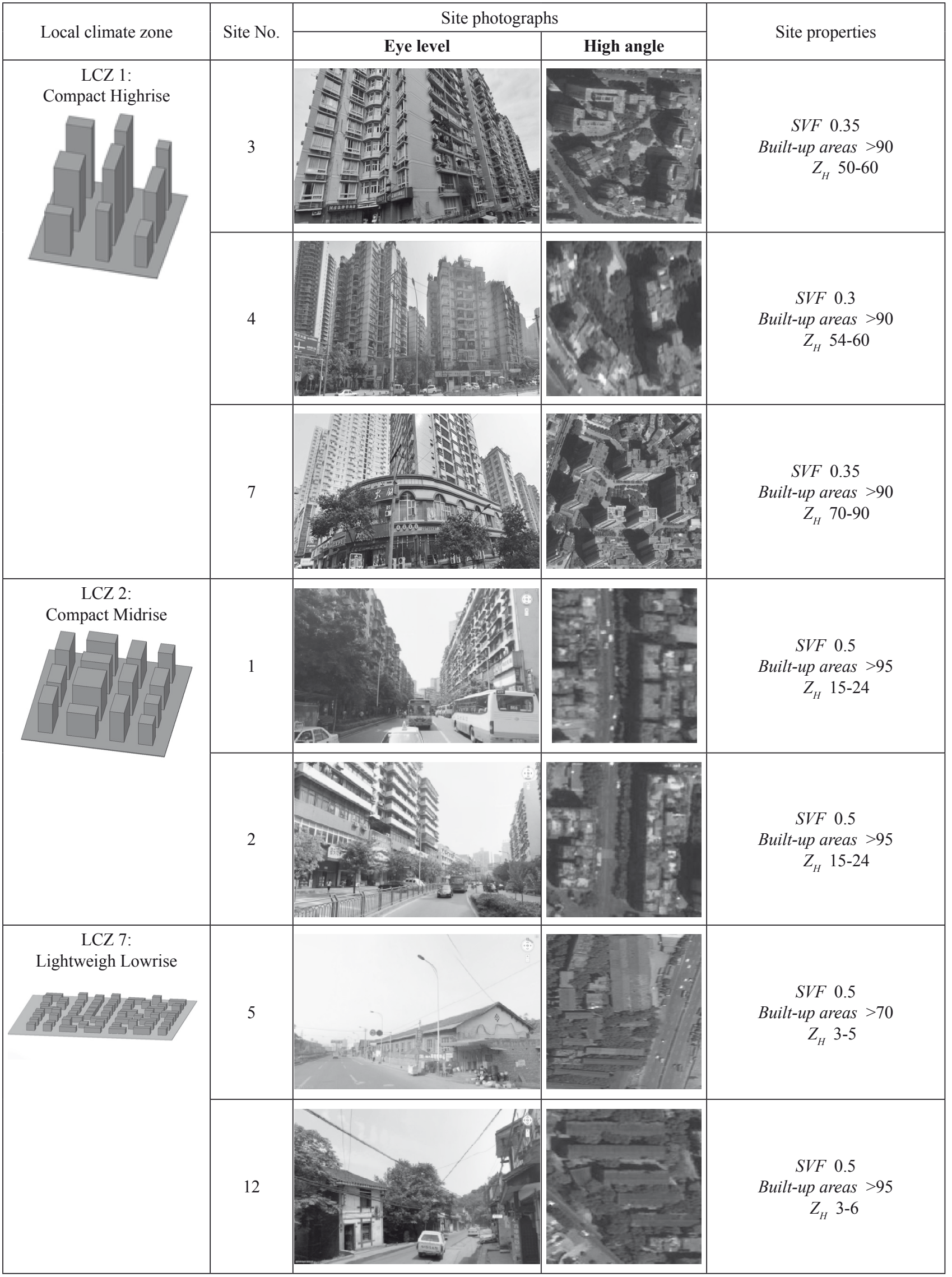


Table 1. Continued.

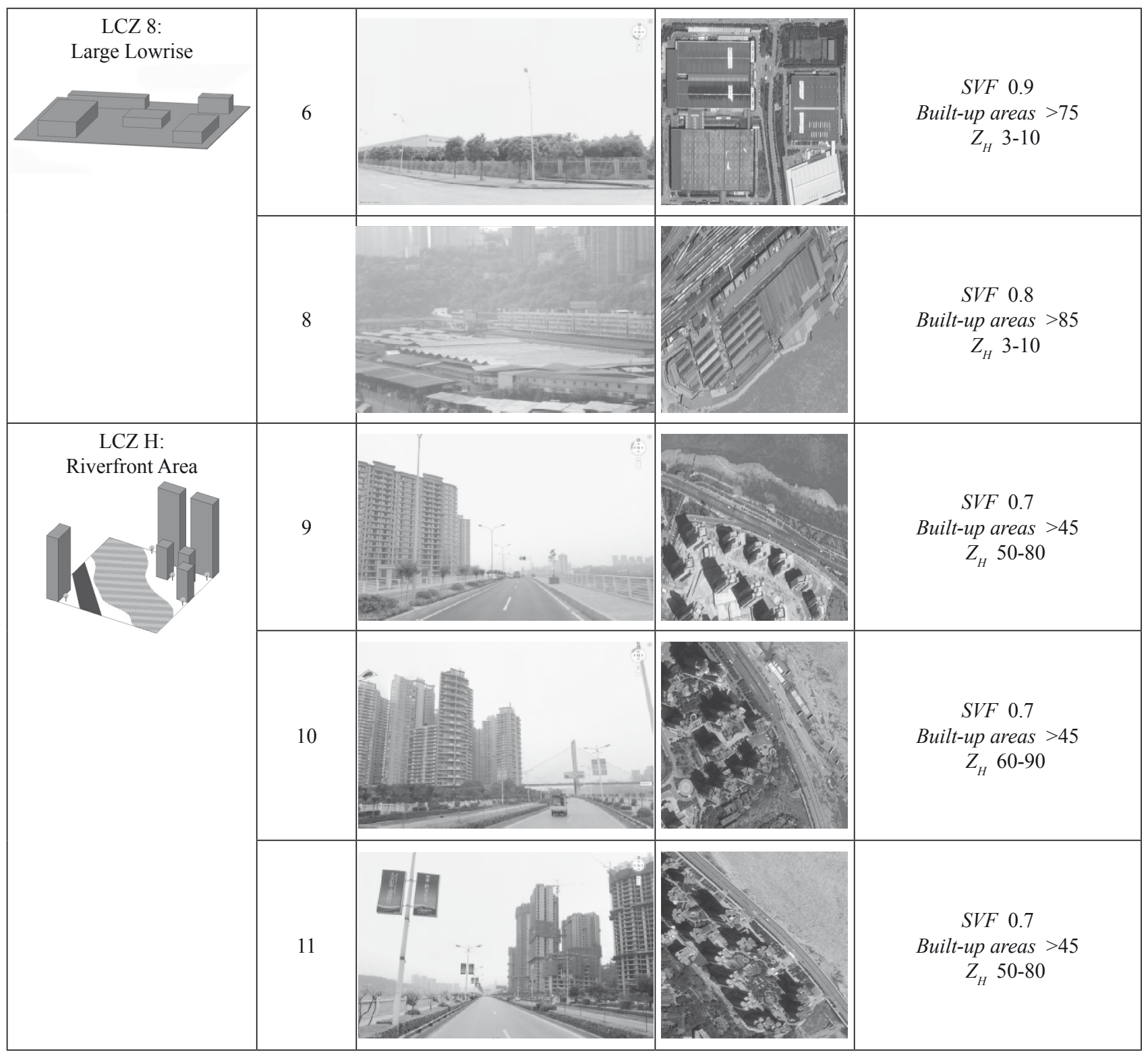

in Shapingba District) to the highest at $379 \mathrm{~m}$ (Eling areas in Yuzhong District), with an average altitude of $264 \mathrm{~m}$. The altitude difference was as great as nearly $200 \mathrm{~m}$, which would cause significant natural air temperature changes. These are also typical climate characteristics of a mountainous city like Chongqing.

Mobile measurements were carried out with an instrumented vehicle. The instruments include automatic temperature and humidity data loggers (HIOKI 3641) and a GPS data logger (GlobalSat DG-100). The automatic temperature and humidity data loggers were made in Japan with accuracy of $0.5^{\circ} \mathrm{C}\left(0.0-35.0^{\circ} \mathrm{C}\right)$. The GPS data logger was made in Taiwan with a SiRF star III wafer. The activation time of all the instruments was set to be in coincidence with the observation time, and the record intervals were set at five seconds.

One automatic temperature and humidity data logger was put in the thermometer screen, which was fixed on top of the car at about $1.5 \mathrm{~m}$ above the ground, and the
GPS data logger was close to the thermometer screen. The speed of the car was controlled to within $40 \mathrm{~km}$ per hour with small variation. At the same time, four other automatic temperature and humidity data loggers were put in the areas of observation routes to record the natural changes of air temperatures in different districts, which are used to correct air temperature data to be synchronous. After the observations, all the recorded air temperature data were corrected to be synchronous at the middle of the observation time span.

\section{LCZ Matching Process}

The first step is to gather metadata, i.e., frequently used climatic indicators that are relevant to estimate or calculate. The commonly used climatic indicators, which are also selected by Stewart and Oke to define local climate zones, include sky view factor (SVF), canyon aspect ratio, mean building height, terrain roughness class 
(TRC), building surface fraction, impervious surface fraction, pervious surface fraction, surface admittance, surface albedo, and anthropogenic heat flux. Metadata can be gathered through satellite images, field surveys, and GIS calculations.

The second step is to determine the source areas. The area of influence for a temperature measurement is that area "seen" by the thermal sensor. It is, in other words, the surface area from which thermal properties are brought, via turbulent transport, to the sensor. All field sites are essentially defined by "areas of influence," or source areas. A "rule of thumb" approach suggests that the size of the source area does not extend a few hundred meters. In [11], source area size is about a 100 m radius for densely built areas and $200 \mathrm{~m}$ for open land areas.

In this study, LCZ contours have been adjusted by calculating some selected urban indicators over 10 . SVF has been calculated by processing images captured with a fisheye lens. TRC has been determined for each LCZ according to the Davenport classification. Building surface fractions and pervious and impervious surface fractions were manually calculated using satellite images. Due to lack of input data, the other urban indicators were not calculated but only estimated according to Stewart's standard datasheets for local climate zones. The source area size is $200 \mathrm{~m}$ radius.

Five measurement sites were selected from the traverse route to determine LCZ thermal differences (Fig. 3, Table 1), which are LCZ type 1, LCZ type 2, LCZ type 7, LCZ type 8 , and LCZ type $H$. The number in a circle means the site number. Route I and route II have the same LCZ types, but route II has one more site number (12), which also belongs to LCZ type 7. LCZ type $\mathrm{H}$ is a riverfront area, which is not included in Stewart's datasheets for LCZ and different from LCZ G. As stated before, the Yangtze and Jialing rivers pass in the center of the urban area, so that a large range of riverfront areas exist in the study areas. Riverfront areas are a representative surface landscape in Chongqing. In Table 1, built-up areas include impervious surface fractions and building surface fractions (\%), and $Z_{\mathrm{H}}$ is the geometric average of building or plant-canopy heights $(\mathrm{m})$.

\section{Results and Discussion}

\section{Air Temperature Amplitude Inside LCZs in Spring}

Screen-height air temperature cross-sections through local climate zones in spring are shown in Fig. 5, in which the $\mathrm{x}$-axis is the distance of the measurement point departure from the starting position and the y-axis shows the average air temperature of each LCZ type. The average air temperature of each LCZ is the average air temperature value of all the recorded points on the measurement route, which is also located in the areas of each LCZ with a given source area size. The difference of spatial mean air temperature inside LCZs in spring is shown in Fig. 6.

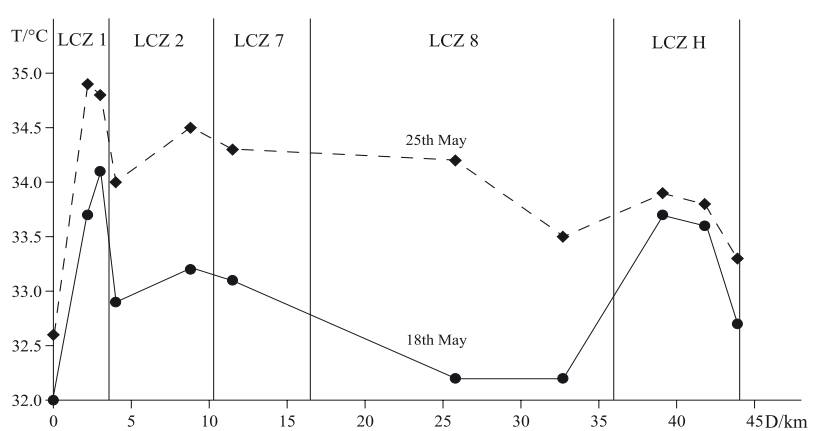

Fig. 5. Temperature cross-sections through local climate zones in spring.

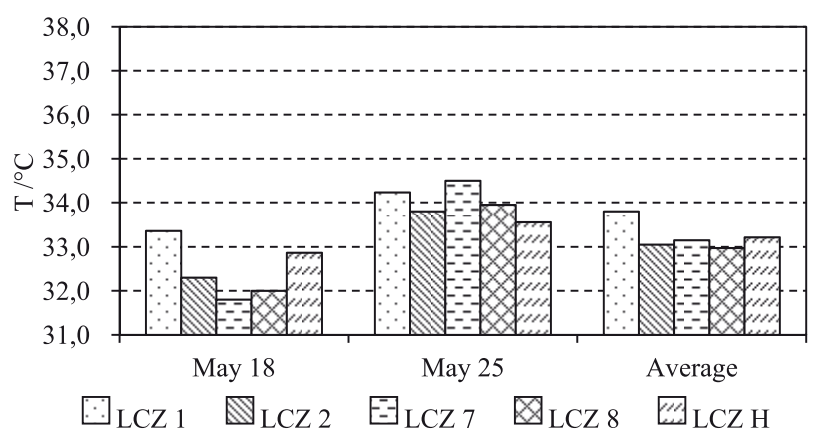

Fig. 6. Difference of spatial mean air temperature inside LCZs in spring.

The air temperature changing trends of the two mobile measurements in spring were accordant in Fig. 5, and the average air temperature during the mobile survey on 25 May $\left(34.0^{\circ} \mathrm{C}\right)$ is one degree higher than that on 18 May $\left(33.0^{\circ}\right)$. It was obvious in Fig. 6 that the average air temperature in each LCZ type showed differences. During the measurement on 18 May, the highest mean air temperature existed in LCZ 1 and the lowest was in LCZ 7. For the 28 May measurement the mean air temperature of LCZ 7 was as high as $34.5^{\circ}$ and was abnormal. The reason causing this might be heat released from other vehicles increasing the recorded air temperature during the measurement session over the road in LCZ 7. Judged from the mean air temperature of the two mobile surveys in spring, the difference of spatial mean air temperature inside LCZs could be concluded. LCZ 1 had highest mean air temperature $\left(33.8^{\circ}\right)$, next is LCZ H, and LCZ $7\left(33.2^{\circ}\right)$, followed by LCZ $2\left(33.1^{\circ}\right)$, and LCZ $8\left(33.0^{\circ}\right)$.

\section{Air Temperature Amplitude Inside LCZs in Summer}

Screen-height air temperature cross-sections through local climate zones in summer are shown in Fig. 7, in which the $\mathrm{x}$-axis is the distance of the measurement point departure from the starting position, and the y-axis shows the average air temperature of each LCZ type. The difference of spatial mean air temperature inside LCZs in summer is shown in Fig. 8. 


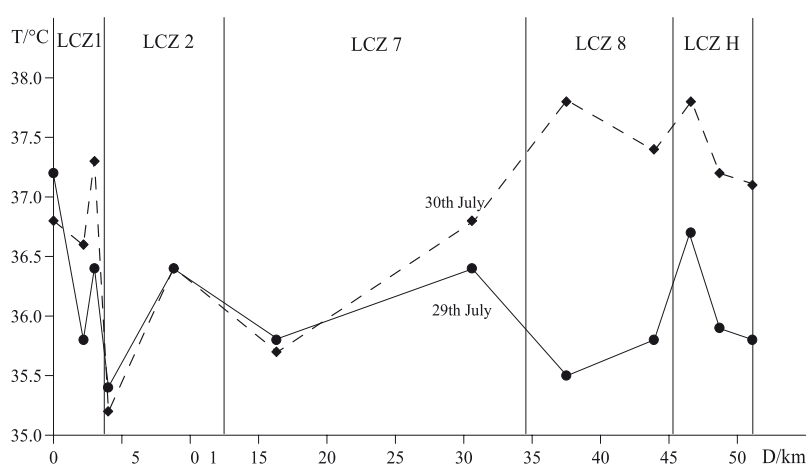

Fig. 7. Temperature cross-sections through local climate zones in summer.

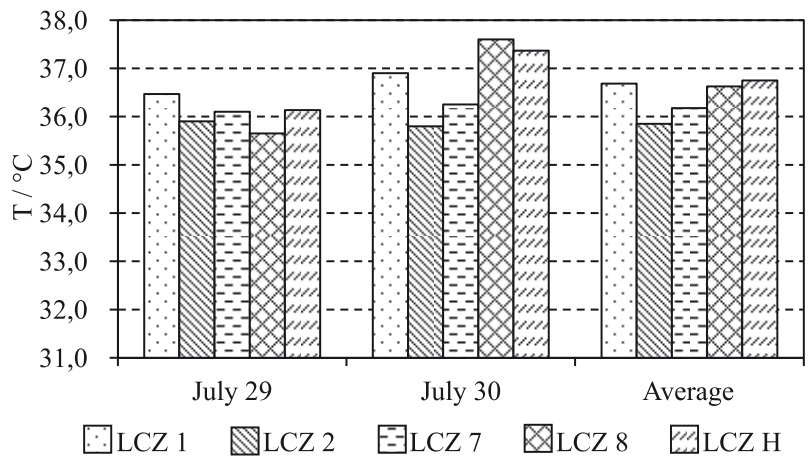

Fig. 8. Difference of spatial mean air temperatures inside LCZs in summer.

The air temperature changing trends of the two mobile measurements in summer were also similar in Fig. 7, except for measurement point numbers $3,1,2$, and 5 . The average air temperature during the mobile survey on 30 July $\left(36.8^{\circ}\right)$ is higher than that on 29 July $\left(36.1^{\circ}\right)$. After analyzing with Fig. 8, LCZ H with $36.8^{\circ}$ had the highest mean air temperature of the two mobile surveys in summer, which was different from the result of the spring measurements. The following is LCZ 1 with $36.7^{\circ}$, which is quite close to the highest value. LCZ 2 had the lowest mean air temperature $\left(35.9^{\circ}\right)$.

\section{Average Air Temperature Differences Inside LCZs}

Seasonal air temperature changes inside LCZs are shown in Fig. 9 after calculating the average value of mobile measurements in the two seasons, which showed an apparent seasonal difference inside LCZs. In LCZ 1, the average air temperature difference was $2.9^{\circ}$ between the two seasons, while in LCZ $\mathrm{H}$ this difference was as large as $3.5^{\circ}$. The average air temperatures for each LCZ fell into the following order: LCZ $1\left(35.2^{\circ}\right)>\mathrm{LCZ} \mathrm{H}$ $\left(35.0^{\circ}\right)>\operatorname{LCZ} 8\left(34.8^{\circ}\right)>\operatorname{LCZ} 7\left(34.6^{\circ}\right)>\operatorname{LCZ} 2\left(34.5^{\circ}\right)$.

With the mobile survey results from Figs 5 to 9, measurement points in LCZ 1 had relatively high air temperatures, which were related to small sky view factor,

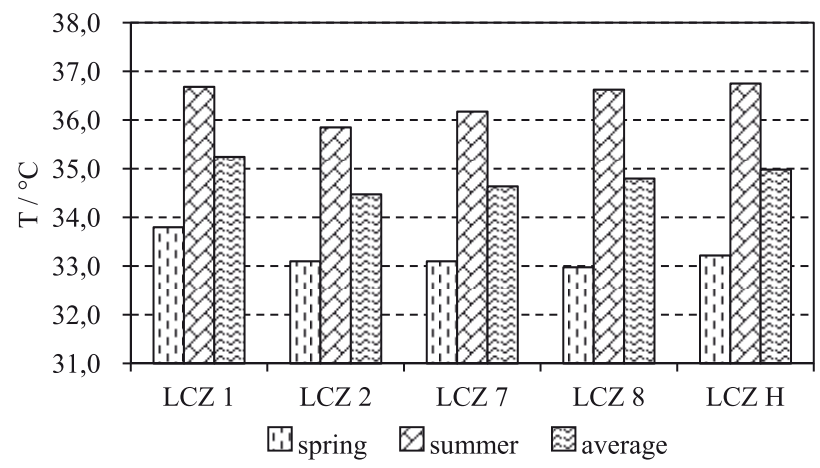

Fig. 9. Seasonal air temperature changes inside LCZs.

large impervious pavement, high capacity of heat storage, and strong traffic heat release. The mean air temperature difference in LCZ 7 and LCZ 8 was small. LCZ number 5 in LCZ 7 and LCZ number 6 and 8 in LCZ 8 had similar micro-scale surface characters. The large sky view factor and solar radiation caused high air temperature in these sites. LCZ number 12, located over a transmeridional street with no shading, resulted in its high air temperature.

Although there are plenty of water bodies located within the urban area of Chongqing, such as the Yangtze River, the Jialing River, etc., it is worth noting that points in LCZ H had relatively high air temperature during the mobile survey. Two reasons were responsible for this. The first is that the points on the riverside road were exposed to the sunshine with little shading and there was massive heat released from heavy traffic on the riverside road; the second was that the elevation of water surfaces were about 20 meters lower than that of the riverside road, and the waters were all surrounded by artificial structures - thus allowing for little natural convection between the cool air above the waters and the surrounding hot air.

\section{Conclusions}

The LCZ scheme has been used in the main city of Chongqing to study the urban heat island. Urban indicator calculations have allowed for identifying existing urban areas to specific types of LCZs according to the standard datasheets for local climate zones proposed by Stewart. A specific LCZ H was introduced as there was a large range of riverfront areas in the study area and it is a unique feature of the landscape in Chongqing.

Screen-height air temperature distribution was investigated inside the LCZs in two seasons. There was an apparent seasonal difference inside the LCZs. Air temperature amplitude was about $0.8^{\circ}$ in spring and $0.9^{\circ}$ in summer inside LCZs. The average air temperature difference in LCZ 1 was $2.9^{\circ}$ between the two seasons, while in LCZ $\mathrm{H}$ this difference was as high as $3.5^{\circ}$. Even though LCZ H was a mixed landscape with water and artificial constructions and was usually not considered to be the urbanized LCZ type, LCZ H indeed had relatively high air temperatures among all the LCZ types. 
The mobile measurement approach could provide highdensity data of screen-height air temperature at regular spatial or temporal intervals. But with no allowance for the underlying surface character, interval sampling does not guarantee that the recorded temperatures will spatially coincide with homogenous source areas. Therefore, LCZ maps need to be built in the areas of interest in further study so that the temperatures recorded by mobile measurement will represent thermal conditions beyond the micro-scale surroundings and guide UHI studies.

\section{Acknowledgements}

This research was supported by the National Natural Science Foundation of China (Grant No. 51308268), the Applied Basic Research Program Foundation of Yunnan Province (2013FD008), and the Talents Introduction Foundation of Kunming University of Science and Technology (KKSY201306029).

\section{References}

1. STEWART I., OKE T. Local Climate Zones for urban temperature studies. Bull Am Meteorol Soc 93, 1879, 2012.

2. ANGELA G., ANNARITA V., GIANLUCA R., NICOLA C., VINICIO M. Dynamic modeling and simulation of buildings energy performance based on different climatic conditions. Int J Heat Tec 33 (4), 107, 2015.

3. CHIARA D., GUGLIELMINA M., LAURA S., GIOVANNI $\mathrm{V}$. The role of urban form and socio-economic variables for estimating the building energy savings potential at the urban scale. Int J Heat Tec 33 (4), 91, 2015.

4. PHELAN P.E., KALOUSH K., MINER M., GOLDEN J., PHELAN B., SILVA H., TAYLOR R.A. Urban Heat Island: Mechanisms, Implications, and Possible Remedies. Annu Rev Env Resou, 40, 285, 2015.

5. LORIDAN T., GRIMMOND C. Characterisation of energy flux partitioning in urban environments, links with surface seasonal properties. J Appl Meteorol Climatol 51, 219, 2012.

6. REN C., NG E., KATZSCHNER L. Urban climatic map studies: a review. Int J Climatol 31, 2213, 2011.

7. OKE T. Initial guidance to obtain representative meteorological observations at urban sites. Tech. Rep. 81. World Meteorological Organization, 2004.

8. STEWART I. Redefining the urban heat island. Doctor of Philosophy. The University of British Columbia. Vancouver Canada. 2011.

9. EMMANUEL R., KRÜGER E. Urban heat island and its impact on climate change resilience in a shrinking city, the case of Glasgow, UK. Build Environ 53, 137, 2012.

10. HOUET T., PIGEON G. Mapping urban climate zone and quantifying climate behaviors - an application on Toulouse urban area (France). Environ Pollut 159, 2180, 2011.

11. STEWART I., OKE T., KRAYENHOFF E. Evaluation of the 'Local Climate Zone' scheme using temperature observations and model simulations. Int J Climatol 34 (4), 1062, 2013.

12. BOKWA A., HAJTO M.J., WALAWENDER J.P., SZYMANOWSKI M. Influence of diversified relief on the urban heat island in the city of Krakw, Poland. Theor Appl Climatol 122 (1-2), 365, 2015.

13. SZEGEDI S., TOTH T., KAPOCSKA L., GYARMATI R. Examinations on the meteorological factors of urban heat island development in small and medium-sized towns in hungary. Carpath J Earth Env 8 (2), 209, 2013.

14. ROTH M., CHOW W.T.L. A historical review and assessment of urban heat island research in Singapore. Singap J Trop Geogr 33 (3), 381, 2012.

15. BRANDSMA T., WOLTERS D. Measurement and statistical modeling of the urban heat island of the city of Utrecht (The Netherlands). J Appl Meteorology Climatol 51, 1046, 2012.

16. SCHWARZ N., SCHLINK U., FRANK U., GROSSMANN $\mathrm{K}$. Relationship of land surface and air temperature and its implication for quantifying urban heat island indicators - an application for the city of Leipzig (Germany). Ecol Indic 18, 693, 2012.

17. LECONTE F., BOUYER J., CLAVERIE R., PÉTRISSANS M. Using local climate zone scheme for UHI assessment: evaluation of the method using mobile measurements. Build Environ 83, 39, 2014. 